\title{
Early Warning Flood Defence System, experience from the field
}

\author{
Rob van Putten ${ }^{1, a}$ \\ ${ }^{1}$ Waternet, Research and Engineering, 1096AC Amsterdam, The Netherlands
}

\begin{abstract}
Waternet and Siemens built an early warning system for the Ringdijk in Amsterdam. The experiences during this project led to a vision on the usage and benefits of such systems. This article is about that vision and the practical experiences during the project. The article shows the context of implementing an early warning system in Dutch practice and describes the promises and proven benefits in an age of upcoming digital technologies and climatological chances.
\end{abstract}

\section{Introduction}

Flooddefence is deeply rooted into Dutch culture. Since The Netherlands literally appeared on the surface, there was an ongoing struggle against the forces of nature. During the last 4 centuries the flood defence systems became more advanced. But even as recently as 1953 made it clear that the fight wasn't over. 1836 people lost their lives during the 'Watersnood ramp'. The 'Deltawerken' were initiated as a result of the 1953 disaster including a secure coastline, bridges, dams and the famous 'Oosterscheldekering'.

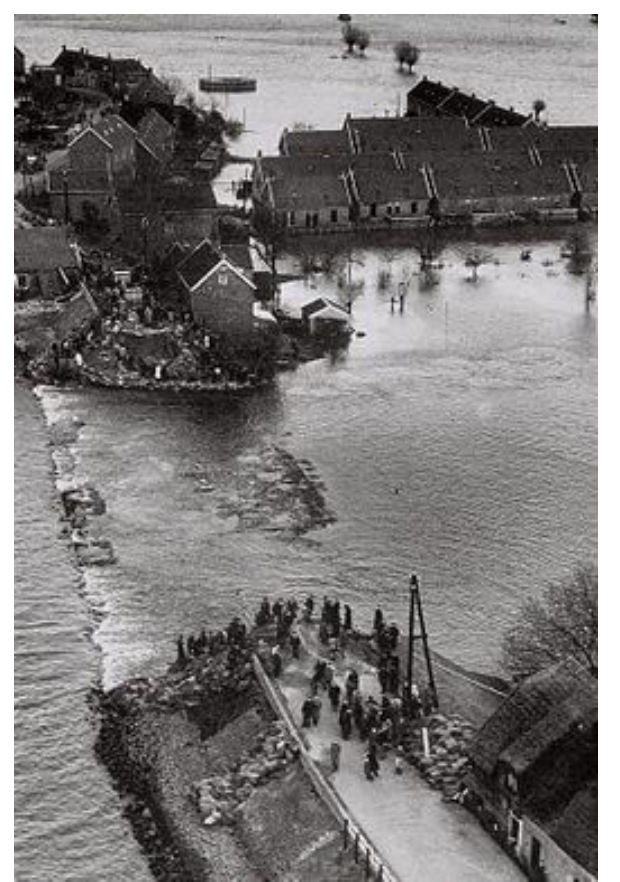

Figure 1. Breach during the 1953 flooding
Today we are living in the digital age and we see the results of the industrialisation on climate change. This poses challenges to a country below sea level. The Netherlands will have to be innovative in the defence against flooding. Advances have been made in modelling and construction, but somehow the big data and artificial intelligence possibilities seem to get little attention, even though they offer great promise in early warning systems flood defence systems.

This paper covers the usage of remote sensor systems, advanced modelling, big data and artificial intelligence in the development of modern early warning systems.

\section{The need for early warning systems}

The Netherlands are home to about 17.500 kilometres of dikes. 3.500 kilometres of that amount are called 'primary dikes'. They protect $66 \%$ of The Netherlands against flooding. The primary dikes are located at seashores and the dikes of the main rivers like the Rhine and Meuse. The remaining 14.000 kilometres of secondary dikes protect the areas around lakes and smaller rivers.

The safety of the majority of the dikes is a joined responsibility of 22 waterboards. At 12 year intervals the dike assessments are carried out to check the safety state of the dikes. About a third of the dikes were concluded to be unsafe during the assessment of 2010-2012.

The investment to reinforce the dikes are roughly estimated at $€ 200.000$ up to $€ 2.000 .000$ or more per kilometre depending on the location and size of the dike. The total investment could add up to billions of euros.

\footnotetext{
${ }^{\mathrm{a}}$ Corresponding author: rob.van.putten@waternet.nl
} 
Apart from these financial implications The Netherlands need to be prepared for the effects of climate change. According to the Dutch weather institute KNMI [1] the following possibilities can be expected;

- $\quad$ Rising temperature

- Less precipitation in summer

- $40 \mathrm{~cm}$ rise of sea level by 2050

- $\quad 80 \mathrm{~cm}$ rise of sea level by 2085

- Increased chance of extreme rainfall

In terms of dike management this means a higher risk of failure due to excessive precipitation, higher water levels and a bigger risk of effects on drought at peat dikes.

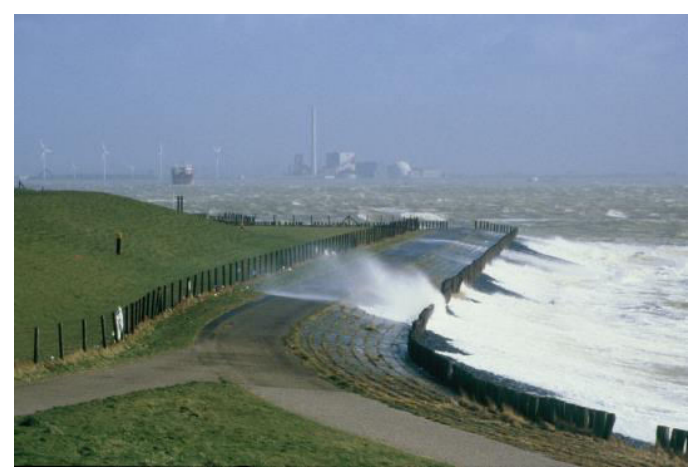

Figure 2. Typical day for a Dutch dike, source; beeldbank.rws.nl, Rijkswaterstaat / Harry van Reeken

Currently uncertainties are handled by using safety factors. Having more uncertainties, like those introduced by climate change, lead to higher uncertainties and as a result to more theoretically unstable dikes again leading to higher investments.

A last but not a trivial challenge in dike safety is the ageing of the population, in combination with the urbanization of the areas below sea level. Dike safety assessments become more complicated and the number of engineers able to do the assessments decreases.

Early warning systems help tackle these problems in a number of ways. The basis of an early warning system is collecting data, running it through a model and checking for imminent failure. Being able to build such a system leads to smart dikes where safety assessments are handled at real time. Combining this information with practical experience by experts and people in the field will result in a thorough system that is able to predict failure without the explicit need of continuous human monitoring.

Collecting data feeds one of the paradigms of science. In Dutch this is called 'meten is weten' which translates to 'to measure is to know'. More data leads to a better understanding of dike behaviour. This in turn leads to better models and predictions. As a result the statistically determined safety and modelling parameters can be optimized which leads to lower and more cost effective investments on dike maintenance.
Having early warning systems in place also leads to an increase in citizen participation and public understanding. Dike safety can be shared using social media, observations on dike safety by citizens can be input to the model and in essence the experiences of the system can be shared worldwide with other countries dealing with flood risks.

It can be stated that early warning systems in dike safety are a logical and effective path in dike safety leading to a safer flood risk system as well as means for better financial planning of investments.

\section{Uncertainties and impact}

Geotechnical engineering is a field of science which has to deal with a lot of uncertainties. Geometrical and spatial variability in three axes as well as soil strength and water levels are sources of uncertainty. The less is known about these uncertainties the more safety is built into the final model and assessment.

\subsection{Soil variability}

Looking at Dutch soil layers and soil properties, there is a wide range of parameters that can be found. This is especially true in deltas like the west of The Netherlands where the location of the rivers moved over time. Figure 3 shows a typical geotechnical profile for the Amsterdam area.

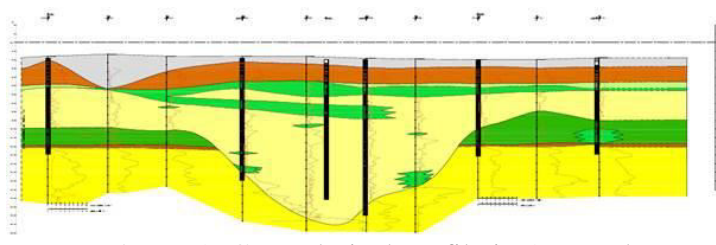

Figure 3. Geotechnical profile in Amsterdam

In figure 3, the interpretation of 6 boreholes and 6 cone penetration tests in an Amsterdam region is shown. Over a length of about 600 meters the soil variability is very large as can be seen by the sand layer (light yellow) cutting through the deep clay (green) and peat (brown) layers. It is clear that the input for the final assessment of this part of the dike should contain at least 3 or 4 different locations based on the geotechnical profile alone.

More generally it can be stated that the amount of material sampled in site characterization boreholes is typically only $10^{-6}$ to $10^{-9}$ of the total site volume [2]. Dutch practice introduced a schematization factor to account for this uncertainty during dike assessments. The value for this factor is in range 1.1 to 1.4 , with the assessed safety factors needing to be divided by this schematization factor.

\subsection{Soil strength}

Currently there is a national discussion on the best method to determine the strength parameters of peat and soft clays. Since 1990 triaxial tests have been used for 
this purpose. Current research [3] recommends switching to the direct simple shear (DSS) tests.

Looking at the used laboratory tests we find a wide variety in the results. Figure 4 shows a typical distribution of soil parameters. Linear fits or even multivariate regression techniques are only rough approximations of the soil strength.

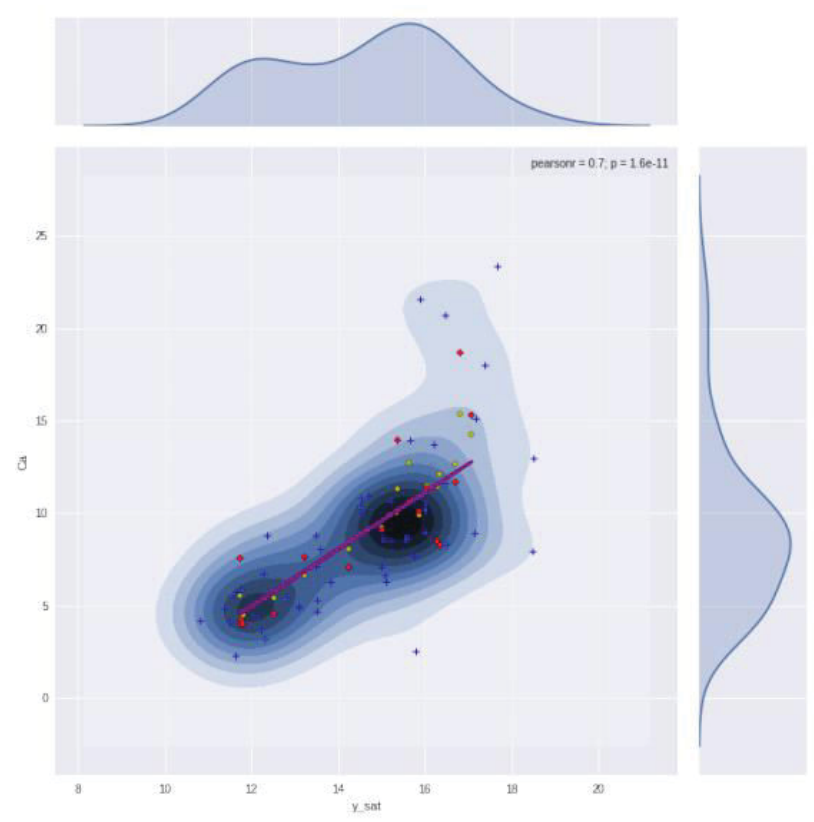

Figure 4. Typical distribution of strength parameters

Looking at Waternet the parameters for peat are determined by the results of 114 triaxial tests. The average value for cohesion is $10.8 \mathrm{kPa}$. This value is reduced to $2.7 \mathrm{kPa}$ in the actual calculation due to statistical analysis and the usage of a material factor. This shows a $75 \%$ percent decrease of the initially found strength parameters and as such can be labelled as a major uncertainty in dike assessments.

\subsection{Water levels}

Another important source of uncertainty is the water level in the dike and the response of the dike to precipitation. Normally during an assessment the water level is measured at different locations, using boreholes and water pressure transducers. The data acquired from these measurements is commonly only recorded during a few weeks. Local precipitation is often not measured at all. This data is used for extrapolation of decisive conditions.

Figure 5 shows long term measurements of the hydraulic head (NAP) at a dike in Amsterdam. During a period of 2 years a fluctuation can be seen between NAP -1.2 up to NAP $-0.4 \mathrm{~m}$.

\section{hydraulic head [m tov NAP]}

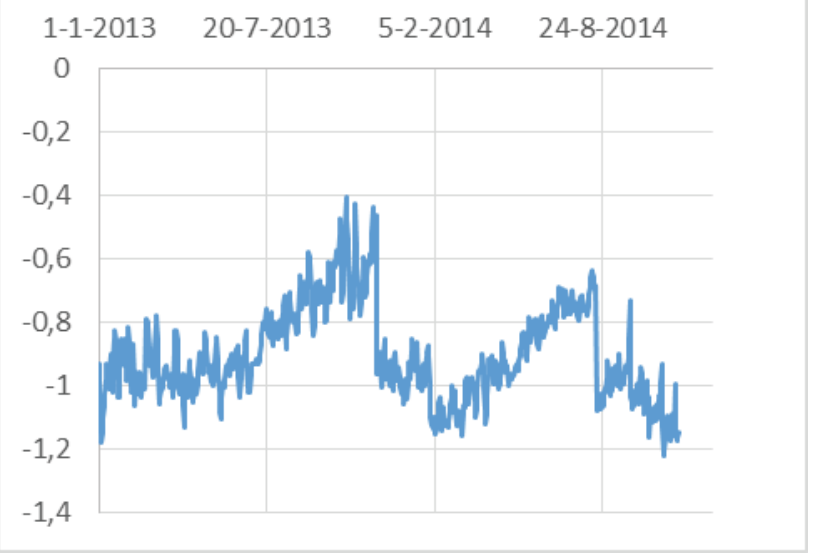

Figure 5. Long term hydraulic head measurements

It is clear that the normal short measurement periods of a few weeks do not cover the entire range of actual water levels. As a result conservative water levels are used in the calculations.

\subsection{Other}

In 2017 the Dutch practice will switch to the critical state soil mechanics model (CSSM) instead of the widely used Mohr-Coulomb model [4]. The soil parameters for peat and light clays will be determined using direct simple shear (DSS) tests instead of the current triaxial tests. Large scale field tests have shown a better fit with these new models mainly due to the possibility to take the load history of the soils into account.

So far there is limited experience on how these methods work for dike assessments. Even though the expectation is a better fit with practice it will take a while to get used to these methods and the interpretation of the results. During this time conservative interpretations of the results will be made.

\subsection{Impact of uncertainties}

Being safe is priority number one and the current methods are safe. The Netherlands is a country which hasn't had a major flooding with casualties since 1953, even though $66 \%$ of the country is liable to flooding.

There is however a turning point in being safe and being excessively safe and this is where the problem arises. Currently about a third of the dikes are unsafe based on the latest assessments. This calls for an investment of billions of euros.

Recent dike failure tests like those done in The Netherlands all show that failure of the dike only happens well after the predicted conditions if these conditions are based on the current practice. The most recent Markermeerdijk test showed that the strength of peat was 
underestimated and higher values for their parameters can be used [5].

We have room for improvement and reduction of costs for flood defence maintenance. We do however not have an immediate answer to the question of how much we can improve the assessments by using less conservative methods and parameters.

\subsection{Uncertainties and EWS}

All presented uncertainties prevent a better understanding of real dike behaviour and although more field tests, laboratory tests and longer measurements will help to build more accurate models there is another way to deal with the uncertainties, which is monitoring. The simple motto 'to measure is to know' applies to geotechnical engineering as well. Acquiring data helps in two ways. It builds up a database of real dike behaviour and it is a way to continuously keep track of the current state of the dike. Collecting enough data even offers the option to predict the dike behaviour in the future.

\section{Test case Ringdijk in Amsterdam}

Uncertainties can be reduced by acquiring more data. The introduction of robotics and its wide range of sensors allows for new possibilities. During the IJkdijk macrostability tests performed by Rijkswaterstaat [6] several companies introduced new measurement techniques. Waternet, a waterboard in the Amsterdam area started to test these sensors and their application in 2011 at a dike in Amsterdam.

\subsection{Test location}

The Ringdijk is a dike in Amsterdam protecting the urbanized polder Watergraafsmeer which lies 4 to 5 meters below sea-level. According to the 2011 dike safety assessment this dike scored low on macrostability. The results showed safety factors well below the required ones. Based on field experience and actual monitoring of the dike the outcome of the assessments was doubted which cleared the path for more and innovative measurements.

In 2011 the Ringdijk was equipped with 17 sensors (geobeads) that measured water pressure, water level, relative inclination as well as water temperature every hour.

During 2011 and 2015 this data was used to build an early warning system. The first ideas were presented during the Urban Flood Commission. An intensive cooperation of Siemens and Waternet led to a complete working prototype.

\subsection{Measurements}

The sensors measured near real time values of water pressure, water temperature and relative inclination at adjustable intervals. An acceptable rate of battery consumption and useable data was found at acquiring data every hour. The sensors were placed at three different depths to make it possible to see the response of different layers on external changes.

Figure 6 shows the hydraulic level in the soil layers during a two year interval.

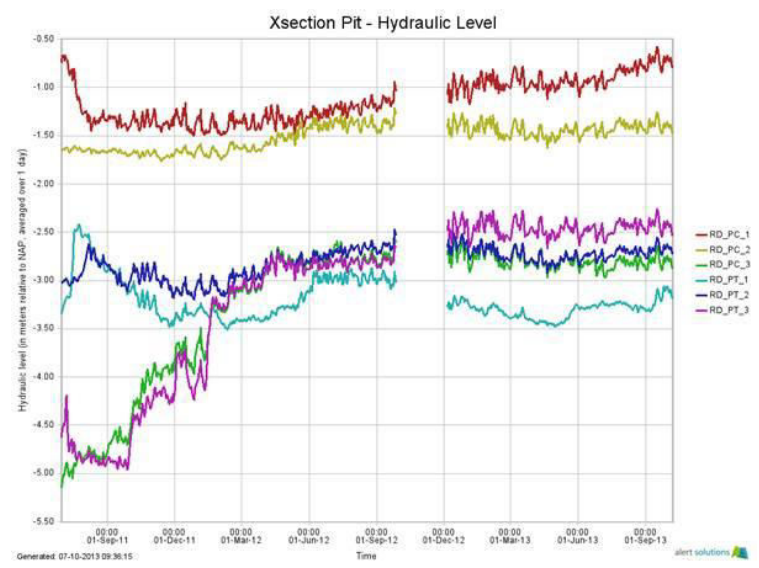

Figure 6. Measurements at the Ringdijk

The measurements are typical for any kind of measurement on dike parameters. There is a lot of noise and variance.

\subsection{First ideas}

Having continuous online data and a model gave rise to the idea to feed the data into the model and create a (near) real time monitoring system.

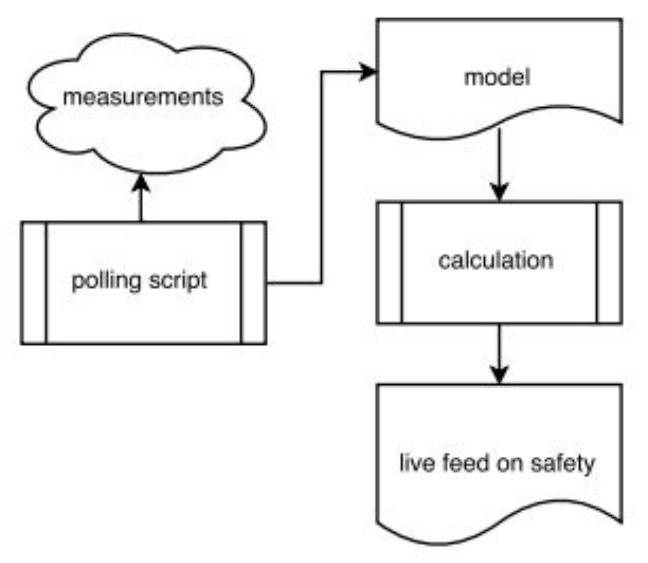

Figure 7 Flow chart of continuous safety assessments

The author built a proof of concept system using an analytical model in just a few days. A script polled the measurements database at regular intervals for new 
measurements. If new measurements where found the script generated a calculation file based on the latest data. Another polling script checked for new calculations and automatically executed the calculation software with the new input and reported this to the user. This basic system enabled a continuous monitoring of the safety factor.

\subsection{Proven strength}

Using methods that are common for dike assessments it was found that the monitored cross section was theoretically unstable during the entire test. The theoretical model discussed in [6] was applied to the outcome of the calculations to incorporate the idea of proven strength.

Based on a Dutch report [7] the strength of the soil is increased based on a situation in which the lowest stability factor where no measurable or visible instability occurred.

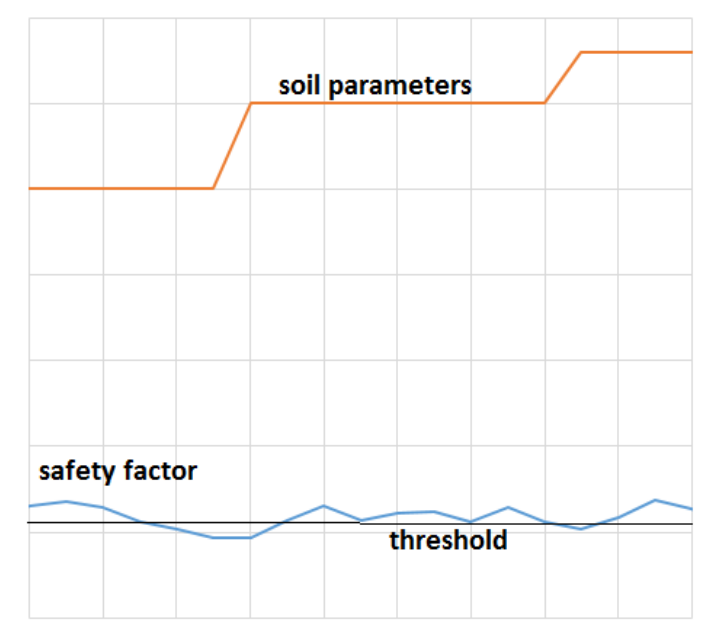

Figure 8 Concept of proven strength

This safety factor is then used to calibrate the soil parameters. The parameters of the old model are updated and form the base of new assessment. This leads to less conservative assessments of the dike stability.

\subsection{Next level}

The development of this proof of concept opened the idea to build a more advanced system. Access to a large amount of data including relative inclination enabled the decision to use geotechnical finite element software called Plaxis.

Siemens was able to make a direct connection between the sensors and the Plaxis model. Since the Plaxis calculations are more resource-hungry than the analytical ones they used a cloud based option which enabled the system to be scalable. In normal operation the calculations were limited to once a day. During exceptional weather this could be scaled up to a calculation every ten minutes. Theoretically the interval is only determined by the scalability of the hardware.
Using finite element instead of analytical software allowed for more accurate calculations. Finite element calculations produce output that includes calculated displacements at every location in the model.

Unfortunately it was not possible to compare these with actual displacements because of the fact that the measured relative inclination could not easily (if at all) be translated to absolute displacements. In general it can be stated that inclination is a suitable parameter to predict failure within a 4-12 hour range [5]. For the Ringdijk experiment the displacements were too low to be of actual value for back analysis.

\subsection{Learn from the past}

By using big data and machine learning approaches, it is possible to create a system that learns the response of the model to external conditions. This concept of machine learning was applied to the EWS at the Ringdijk.

Historical data from previous experiments as well as from the Ringdijk measurements were stored in a database which was input to a training set for the artificial intelligence (AI). The AI's task was to detect anomalies based on machine learning using deep learning / neural networks combined with physical modelling [9, 10]. During the IJkdijk tests in 2012 this technique proved to be able to predict failure [5].

For the Ringdijk the outcome of this system was in accordance with the findings of both analytical calculations using updated strength parameters and the practical experience of dike inspectors.

Another interesting finding was the measured phreatic (ground) water level. In October 2015 more than $80 \mathrm{~mm}$ of precipitation in only a few hours were measured. This amount of rain comes close to the normative amount. The measurements of the phreatic level did not exceed older maxima. This meant an important thing; the dike already survived worse conditions and having this amount of rain again under the same conditions will very likely not affect the dike.

\subsection{Predicting the future}

Statistical algorithms like ensemble and machine learning algorithms like multivariate regression or deep learning are powerful tools for predicting future states. One of the decisive parameters for dike stability is the height of the phreatic water level. This height is mostly determined by the water level in the river, the amount of precipitation and permeability of the soils. Being able to predict the amount of precipitation and its effect on the phreatic level is of great value in the prediction of dike stability.

During the last months of the project, precipitation was measured. This proved to be a difficult task due to 
bird droppings and other typical urban problems like theft and damage to the equipment. This meant that there was too little time to incorporate precipitation and the prediction of the phreatic water level into the project.

The general idea is that parameters like precipitation, drought, air pressure, humidity and temperature are relevant data to form features for deep learning. This technique would enable us to better predict the phreatic level and make more accurate predictions of the dike safety.

\subsection{Caveats}

Building an EWS is a great way to fit models with reality, at the same time protect people and save money because of the possible usage of measurement data to increase strength parameters. However, there are things to be aware of which need further research.

\subsubsection{Sensor data}

It can be hard to acquire good sensor data. Looking at water pressure, it is a known fact that clay and peat do not work very well with the current sensors. Peat can build up gasses that influence the measurements and clay can slowly clog the sensor until it doesn't work at all. During the Ringdijk experiment no sensor failure occurred but in general it is known that within Waternet normal routines about $20 \%$ of the sensors fail due to clogging, damaging, theft etc.

Measuring real inclination is hard and / or expensive. Relative inclination is not a good indicator of failure unless large deformations are measured. In the second half of 2016 Waternet will conduct an experiment using real-time horizontal and vertical deformation measurements combined with a finite element model to see if the measured deformations can be used for back analysis of strength parameters.

\subsubsection{Local to global}

Having information on one or more dike profiles tells a lot about that location. The idea of proven strength will perfectly fit that location. Extrapolation of the outcome to larger stretches of dike requires in depth knowledge and understanding of the variables and their limits. A probabilistic approach is recommended.

Note that the problem with extrapolation is not new. Every dike assessment makes assumptions based on local research and then extrapolates this to the entire dike. The danger of errors in this extrapolation is handled by using safety factors. In case of an EWS the dangers are handled by actual measurements and a statistical approach for extrapolation to the entire dike.

\section{Summary and final notes}

Early warning systems show a promising and logical future for dike safety. Techniques like machine learning, artificial intelligence, and the affordability and growing amount of sensors, enable us to build systems that can act autonomously in a chaotic world. Combining these systems with field data and experiences will lead to better models and more cost effective dike maintenance.

Siemens and Waternet have shown the possibility to build an early warning system for dikes based on the presented techniques. IJkdijk tests have proven that the systems are able to predict failure. Dutch governance is increasingly based on open data, data sharing and big data. Sensors and other hardware are getting cheaper by the day. All ingredients for a bright future for a smart dike maintenance system are in place. It's up to policy makers, engineers and scientists to deliver the final set pieces and start implementing real time early warning systems for flooding.

\section{References}

1. Hurk, van den B., Siegmund, Peter et al, KNMI 14: Climate Change scenarios for the $21^{\text {st }}$ Century - A Netherlands perspective, KNMI WR 2014-01, 2014

2. Journel, A.G., Alabert, F., Non Gaussian data expansion in earth sciences, Terra Nova, 1(2):123134, 1989

3. Duinen, van A., Guide to determination of soil strength parameters (Dutch article), Deltares report 1209434-003, 2014

4. Zwanenburg, Cor, On the determination of soil parameters for peat (Dutch article), Geotechniek juli 2013 26-32)

5. Vries, de, G., Brake, ter, C.K.E., Bruijn, de, H., Koelewijn, A.R., Langius, E.A.F., Lottum, van, H. \& Zomer, W.S. Dijkmonitoring: beoordeling van meettechnieken en visualisatiesystemen. (Dutch) Amersfoort: STOWA/Stichting IJkdijk, 2013

6. Weijers, J., Elbersen, G.T., Koelewijn, A.R., Pals, N, Macrostabiliteit IJkdijk: Sensor- en meettechnologie, Rijkswaterstaat, 2008

7. Putten, R. van, Dijk optimaliseren met sensoring, Geotechniek December 2013 p56-58, 2013

8. TAW, Onderzoeksrapport voor de bepaling van de actuele sterkte van rivierdijken (Dutch report), Technische Adviescommissie voor de Waterkeringen, 1996

9. Pyayt, A., Data-Driven methods in application to flood defence systems monitoring and analysis, 2014

10. Melnikova, N., Finite Element Analysis of Dike Stability for Flood Early Warning Systems, 2014 